e-Neuroforum 2016 · 7:45-47

DOI 10.1007/s13295-016-0030-6

Published online: 18 October 2016

(c) The Author(s) 2016. This article is available at SpringerLink with Open Access.

CrossMark

\title{
Moritz Helmstaedter
}

Department of Connectomics, Max Planck Institute for Brain Research, Frankfurt am Main, Deutschland

\section{Connectomics at cellular precision}

ments are the standard method in these fields, the question whether structural information about nerve cell networks can provide insights about the function of nervous systems is still open and urgent. Especially since substantial methodological efforts and substantial resources have to be invested for complete circuit mapping in cellular connectomics, the purpose of such research is still highly disputed and questioned (see for instance $[2,8])$. The following shall briefly summarize the so far obtained scientific evidence for the inference of functional insights from nerve cell network structure and indicate where such evidence is still missing.

\section{Connectomics in the sensory periphery}

The primary success of cellular connectomics has been the clarification of how directional signals are computed in the visual system of the fly and the mammalian retina. Already more than 50 years ago, Barlow and Levick [3] discovered that certain types of ganglion cells in the retina selectively respond to directed motion in the visual field ("direction selectivity"). Ever since, numerous theoretical and experimental studies have been conducted to elucidate such specific functional selectivity. Is this functional phenomenon implemented by specific nerve cell connections or rather an effect of subtle modifications of synapse strength - or other "dynamic" computational processes? The answer to these questions is rather clear by now: Direction selectivity in the mammalian retina is first encoded in certain amacrine cells; then these amacrine cells transmit the direction selectivity highly specifically to the corresponding gan- glion cells via specific targeted synaptic wiring. This is the mechanism by which the ganglion cells obtain their direction selectivity [7]. The specificity of this innervation is even operating at the level of single dendrites of the amacrine cells (thus highly selectively) and the synaptic imbalance is about 13 fold (i. e. about 13 times more synapses are established in the computationally appropriate direction than in the inverse direction).

The origin of direction selectivity in the amacrine cells has also been studied, and in the meantime substantial evidence has been found that this computation is also implemented via targeted neuronal wiring $[10,16]$. A recently published study was even able to show that depending on the size of the animals' eyes and thus their retinae, different species adapt the neuronal wiring responsible for the direction selectivity computation in order to be able to optimally respond to the movement velocities of visual signals on their respective retina [10].

Thus it is beyond any doubt that in the sensory periphery of the mammalian nervous system the opportunities of implementing neuronal computations via connectomic specificities is extensively made use of. Most interestingly, analyses in the visual system of the fruit fly have provided evidence that comparable connectomic principles are being used in the circuits of this rather evolutionarily distant animal [22]. However, the precise identity of the neurons involved is still controversial ([19, 22]; see also [5] for an extended discussion).

The connectome of the optical system of insects and the visual periphery of mammals can thus be considered clear evidence that in these systems specific nerve cell connections are used to imrelevance of structural data for a detailed understanding, and structural measure- 
plement the algorithms relevant for the animal's behavior.

\section{Cellular connectomics of the cerebral cortex}

What's the status of cellular connectomics of the mammalian cerebral cortex? This part of the mammalian brain contains about 16 bn nerve cells [1] and about 160 trillion chemical synapses in the human brain (these numbers are about 1000 fold less in the mouse brain). Connectomic studies of the cerebral cortex thus require the analysis of substantial tissue volumes which are so far resisting extensive connectomic mapping because of the highly non-local wiring of every single cortical nerve cell.

But is connectomic analysis in the cerebral cortex worth the effort? A simple analogy based on the insights from the mammalian retina is dangerous - as much as the fact that connectomes may have been of limited value in the worm C. elegans or the stomatogastric ganglion of the lobster did not allow conclusions about the relevance of connectomes in the visual systems of fly and mouse.

Whether the structure of nerve cell networks in the cerebral cortex is essential for concrete neuronal computations and at which precision are open questions. Connectomic studies in the cerebral cortex have so far been carried out in tissue blocks of only about 50-70 micrometer thickness $[4,17]$. This size limitation also limited the possible insights about the precision of network architecture in cortex. The recently published, first locally dense reconstruction from mouse cortex [15] was limited to about $10 \times 10 \times 30$ cubic micrometers tissue volume. This data was able to enforce evidence that the direct touch of nerve cells has only limited predictive value for the existence of chemical synapses between these nerve cells (see also [21]). The question whether pairwise random connectivity dominates also at the level of entire axons and nerve cells (so-called "Peter's rule", [6]) or whether highly specific nerve cell networks are being established in the cerebral cortex has thus still to be considered unanswered.
Interestingly, theoretical studies have shown that even mostly randomly wired circuits allow relevant computations [18] and can generate structured maps as representations of the sensory world [14]. Whether the mammalian cerebral cortex is operating in such a random connectivity regime or is rather using precise connections as in the sensory periphery is a major open scientific question.

Substantial research efforts are undertaken to systematically map connectomes in the cerebral cortex. An important focus is on comparative connectomic analysis-fueled by the notion that such comparative mapping can provide insights into circuit invariances and structural principles (see [13] for a summary). The mapping and analysis of cortical connectomes is receiving substantial funding in the US by the research initiative of the intelligence agencies IARPA [20] — also driven by the hope that algorithmic insights for improved machine-based data analysis could be gained from analyzing the circuits in mammalian brains. The new DFG priority program Computational Connectomics [9] is now providing appropriate support at least for the theoretical analysis of connectomic data in Germany-which should now be put to use.

\section{Corresponding address

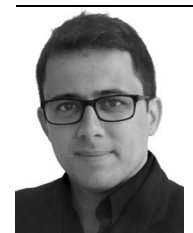 \\ Dr. med. Dipl. Phys. \\ M. Helmstaedter \\ Department of Connectomics, Max Planck Institute for Brain Research \\ Max-von-Laue-Str. 4, 60438 Frankfurt am Main, Deutschland mh@brain.mpg.de}

Dr. med. Dipl. Phys. Moritz Helmstaedter, born in 1978 in Berlin, Germany; from 1998 onwards studied medicine and physics at Ruprecht Karls University Heidelberg, Germany; doctoral thesis with Bert Sakmann and post-doc with Winfried Denk at the Max Planck Institute for Medical Research in Heidelberg; from 2011-2014 Research Group leader and Principal Investigator at the Max Planck Institute of Neurobiology, Munich. Since August 2014 Scientific Member of the Max Planck Society and Director at the Max Planck Institute for Brain Research in Frankfurt am Main, Germany.

\footnotetext{
Open access funding provided by Max Planck
} Society.
e-Neuroforum 2016 · 7:45-47

DOI 10.1007/s13295-016-0030-6

(c) The Author(s) 2016. This article is

available at SpringerLink with Open Access.

\section{Helmstaedter \\ Connectomics at cellular precision}

\section{Abstract}

The complete mapping of neuronal circuits in at least parts of brains has received substantial attention recently. Methodological breakthroughs have made the imaging of ever larger tissue blocks realistic using 3-dimensional electron microscopy. Analysis of such data, however, is still limiting the neuroscientific insights obtainable from cellular connectomics data. What is the state of this scientific field, which insights have been obtained, which are in reach? This brief overview summarizes the current knowledge in cellular connectomics.

Keywords

Connectomics - Electron microscopy .

Cerebral cortex . Neuronal circuits

\section{Compliance with ethical guidelines}

Conflict of interest. M. Helmstaedter declares that he has no competing interest.

This article does not contain any studies with human participants or animals performed by the author.

Open Access. This article is distributed under the terms of the Creative Commons Attribution 4.0 International License (http://creativecommons.org/licenses/by/ 4.0/), which permits unrestricted use, distribution, and reproduction in any medium, provided you give appropriate credit to the original author(s) and the source, provide a link to the Creative Commons license, and indicate if changes were made.

\section{References}

1. Azevedo FA, Carvalho LR, Grinberg LT, Farfel JM Ferretti RE, Leite RE, Filho JW, Lent R, HerculanoHouzel S (2009) Equal numbers of neuronal and nonneuronal cells make the human brain an isometrically scaled-up primate brain. J Comp Neurol 513(5):532-541

2. Bargmann Cl, Marder E (2013) From the connectome to brain function. Nat Methods 10(6):483-490

3. Barlow HB, Levick WR (1965) The mechanism of directionally selective units in rabbit's retina. JPhysiol 178(3):477-504

4. Bock DD, Lee WC, Kerlin AM, Andermann ML, Hood G, Wetzel AW, Yurgenson S, Soucy ER, Kim HS, Reid RC (2011) Network anatomy and in vivo physiology of visual cortical neurons. Nature 471(7337):177-182 
5. Borst A, Helmstaedter M (2015) Common circuit design in fly and mammalian motion vision. Nat Neurosci 18(8):1067-1076

6. Braitenberg V, Schütz A (1991) Anatomy of the cortex - Peter's rule and White's exceptions. Springer, Berlin, pp 109-112

7. Briggman KL, Helmstaedter M, Denk W (2011) Wiring specificity in the direction-selectivity circuit of the retina. Nature 471(7337):183-188

8. CNS (2016) Great Debate on Connectomics, Anthony Movshon vs. Moritz Helmstaedter. Connectomics debateCNSNew York. https://www. cogneurosociety.org/watch-the-great-debateconnectomics/

9. Information for Researchers (2016) Priority Programme "Computational Connectomics" (SPP 2041) No. 23, 13. Mai 2016 http://www.dfg.de/en/ research_funding/announcements_proposals/ 2016/info_wissenschaft_16_23/index.html

10. Ding H, Smith RG, Poleg-Polsky A, Diamond JS, Briggman KL (2016) Species-specific wiring for direction selectivity in the mammalian retina. Nature 535(7610):105-110

11. Helmstaedter M (2013a) Cellular-resolution connectomics: challenges of dense neural circuit reconstruction. Nat Methods 10(6):501-507

12. Helmstaedter M (2013b) Connectomics: Neue Methoden zur dichten Rekonstruktion neuronaler Schaltkreise. Neuroforum 1(13):22-25

13. Helmstaedter M (2015) The mutual inspirations of machine learning and neuroscience. Neuron 86(1):25-28

14. Kaschube M, Schnabel M, Lowel S, Coppola DM, White LE, WolfF (2010) Universality in the evolution of orientation columns in the visual cortex. Science 330(6007):1113-1116

15. Kasthuri N, Hayworth KJ, Berger DR, Schalek RL, Conchello JA, Knowles-Barley S, Lee D, VazquezReina A, Kaynig V, Jones TR, Roberts M, Morgan JL, Tapia JC, Seung HS, Roncal WG, Vogelstein JT, Burns R, Sussman DL, Priebe CE, Pfister H, Lichtman JW (2015) Saturated reconstruction of a volume of neocortex. Cell 162(3):648-661

16. Kim JS, Greene MJ, Zlateski A, Lee K, Richardson $M$, Turaga SC, Purcaro M, Balkam M, Robinson A, Behabadi BF, Campos M, Denk W, Seung HS, Wirers E (2014) Space-time wiring specificity supports direction selectivity in the retina. Nature 509(7500):331-336

17. Lee WC, Bonin V, Reed M, Graham BJ, Hood G GlattfelderK, ReidRC (2016) Anatomy and function of an excitatory network in the visual cortex. Nature 532(7599):370-374

18. Maass W, Natschlager T, Markram H (2002) Realtime computing without stable states: a new framework for neural computation based on perturbations. Neural Comput 14(11):2531-2560

19. Mauss AS, Pankova K, Arenz A, Nern A, Rubin GM, Borst A (2015) Neural circuit to integrate opposing motions in the visual field. Cell 162(2):351-362

20. Machine Intelligence from Cortical Networks (MICRoNS) (2015) IARPA. http://www.iarpa.gov/ index.php/research-programs/microns.

21. Mishchenko Y, Hu T, Spacek J, Mendenhall J, Harris KM, Chklovskii DB (2010) Ultrastructural analysis of hippocampal neuropil from the connectomics perspective. Neuron 67(6):1009-1020

22. Takemura SY, Bharioke A, Lu Z, Nern A, Vitaladevun S, Rivlin PK, Katz WT, Olbris DJ, Plaza SM, Winston P, Zhao T, Horne JA, Fetter RD, Takemura S, Blazek K, Chang LA, Ogundeyi O, Saunders MA, Shapiro V, Sigmund C, Rubin GM, Scheffer LK, Meinertzhagen IA, Chklovskii DB (2013) A visual motion detection circuit suggested by Drosophila connectomics. Nature 500(7461):175-181 